\title{
Genetic variants within the cancer susceptibility region 8 q24 and ovarian cancer risk in Han Chinese women
}

\author{
Jing Han ${ }^{1,2}$, Jing Zhou ${ }^{1,3}$, Hua Yuan ${ }^{4}$, Longbiao Zhu ${ }^{4}$, Hongxia Ma ${ }^{1,3}$, Dong Hang ${ }^{1,3}$, \\ Dake $\mathbf{L i}^{5}$ \\ ${ }^{1}$ Department of Epidemiology and Biostatistics, School of Public Health, Nanjing Medical University, Nanjing 211166, China \\ ${ }^{2}$ Department of Epidemiology, Nanjing Medical University Affiliated Cancer Institute of Jiangsu Province, Nanjing 211166, \\ China \\ ${ }^{3}$ State Key Laboratory of Reproductive Medicine, Nanjing Medical University, Nanjing 211166, China \\ ${ }^{4}$ Jangsu Key Laboratory of Oral Disease, Nanjing Medical University, Nanjing 210029, China \\ ${ }^{5}$ Department of Gynaecology, Jiangsu Provincial Hospital of TCM, Affiliated Hospital of Nanjing University of TCM, Nanjing \\ 210005, China \\ Correspondence to: Dong Hang, email: hangdong@njmu.edu.cn \\ Dake Li, email: lidake2002@163.com
}

Keywords: ovarian cancer, Han Chinese women, $8 q 24$ region, variant

Received: December 28, $2016 \quad$ Accepted: March 28, $2017 \quad$ Published: April 05, 2017

Copyright: Han et al. This is an open-access article distributed under the terms of the Creative Commons Attribution License (CC-BY), which permits unrestricted use, distribution, and reproduction in any medium, provided the original author and source are credited.

\section{ABSTRACT}

Accumulating evidence suggests that genetic variants at chromosome 8q24 confer susceptibility to various types of cancer. This case-control study was designed to explore the relationship between genetic variants at 8 q24 and ovarian cancer risk in Han Chinese women. Two variants ( $r$ 13281615 A > G and rs6983267 T > G) were genotyped in 377 ovarian cancer cases and 1034 cancer-free controls using TaqMan allelic discrimination assay. Logistic regression analysis revealed that the $G$ allele of rs6983267 was significantly associated with increased risk of ovarian cancer (additive model: adjusted $\mathrm{OR}=1.21,95 \% \mathrm{CI}=1.01-1.43, P=0.048$; recessive model: adjusted $\mathrm{OR}=1.51,95 \%$ $C I=1.06-2.15, P=0.023)$. However, no significant association was observed between rs13281615 and ovarian cancer. In stratified analysis, the risk effect of rs6983267 variant remained significant in premenopausal women (additive model: adjusted OR $=1.62,95 \% \mathrm{CI}=1.18-2.23, P=0.003)$. Summarily, this study suggested that $8 \mathrm{q} 24$ rs6983267 may contribute to the susceptibility of ovarian cancer in premenopausal Han Chinese women, supporting the pleiotropy of $8 q 24$ in carcinogenesis.

\section{INTRODUCTION}

Ovarian cancer is the leading cause of cancer mortality among global women, with an estimation of 240,000 new cases and 150,000 deaths in 2012 [1]. Up to now, the specific etiology of ovarian cancer remains to be determined. It has been proposed that environmental and behavioral factors may play significant roles in ovarian cancer, such as occupation [2], parity [3], oral contraceptive use [4], and family history of cancer [5]. Furthermore, growing evidence has suggested that genetic variants may also contribute to the risk of ovarian cancer [6].

A segment of $1 \mathrm{Mb}$ within chromosome $8 \mathrm{q} 24$ has emerged as a susceptibility region for multiple cancers, including prostate, colon, breast, and ovarian cancers, in genome-wide association studies (GWAS) [7-10].
This region contains no known genes but is bounded at its telomeric end by oncogenes $c-M Y C$ and PVT1. Overexpression of $c-M Y C$ occurs in various types of cancer including ovarian cancer, and reduction of $c-M Y C$ expression by RNA interference can inhibit tumor growth [11]. An association between $c-M Y C$ expression and risk allele of rs6983267 at 8q24 was revealed in colorectal cancer. In addition, a noncoding RNA PVT1 plays an important role in carcinogenesis, and the increase of $P V T 1$ expression was shown to relate with the GG genotype of rs13281615 at 8q24 [12].

Despite the critical role of $8 \mathrm{q} 24$ variants in cancer susceptibility, there has been no study examining the relationship between $8 \mathrm{q} 24$ and the risk of ovarian cancer in Chinese women. Therefore, we conducted this casecontrol study with 377 cases and 1034 healthy controls 
to explore the association of two potentially functional variants, rs6983267 and rs13281615 at 8q24 with ovarian cancer risk in Han Chinese women.

\section{RESULTS}

Demographic and clinical characteristics of 377 ovarian cancer cases and 1034 cancer-free controls are presented in Table 1 . The primary pathological type of cases was epithelial ovarian cancer $(86.7 \%)$. A total of 103 $(27.3 \%)$ patients were diagnosed at stage I or II, and 274 $(72.7 \%)$ were at stage III or IV. The age, occupation, and family history of cancer were comparable between cases and controls (all $P>0.05$ ). However, ovarian cancer cases were more likely to have early menarche age, abortion history, and postmenopausal status, but less likely to use oral contraceptives than cancer-free controls (all $P<0.05$ ).

The genotype distributions of rs13281615 and rs6983267 are shown in Table 2. Calling rates of the two variants were above $99 \%$ and their genotype frequencies in the control group were consistent with Hardy-Weinberg equilibrium $(P>0.05)$. No obvious linkage disequilibrium between the two variants was detected by LD analysis $\left(D^{\prime}=0.155, r^{2}=0.015\right)$. A significant association was observed between rs6983267 and ovarian cancer risk (additive model: adjusted $\mathrm{OR}=1.21,95 \% \mathrm{CI}=1.01-1.43$, $P=0.048$; recessive model: adjusted $\mathrm{OR}=1.51,95 \% \mathrm{CI}$ $=1.06-2.15 P=0.023)$. However, there was no significant association between rs13281615 and ovarian cancer risk.

Furthermore, stratified analysis of the associations was performed according to demographic and clinical variables (Table 3 and Supplementary Table 2). The risk effect of rs6983267 on ovarian cancer was shown to be significant in premenopausal women (additive model: adjusted $\mathrm{OR}=1.62,95 \% \mathrm{CI}=1.18-2.23, P=0.003)$, with significant heterogeneity in strata of menopausal status $(P=0.037)$.

\section{DISCUSSION}

In the current study, we investigated the relationship between two variants (rs6983267 and rs13281615) at 8q24 identified by the GWAS of multiple cancers and ovarian cancer risk. We revealed that the $\mathrm{G}$ allele of rs6983267 was significantly associated with increased risk of ovarian cancer in premenopausal Han Chinese women.

Chromosomal $8 \mathrm{q} 24$ has been considered the most important susceptibility region for various types of malignancy, including prostate [7, 13], colorectal [14-16], and breast cancer [9, 17]. However, the mechanism by which 8q24 variants affect cancer susceptibility is not fully understood. None of identified variants reside within known genes, of which there are few across 8q24. Functional evidence has indicated that this risk region may act as a regulatory hub by physical interactions with several neighboring genes important for carcinogenesis such as $c-M y c$ and PVT1 [18]. Oncogene $c-M y c$ encodes phosphoproteins that participate in the regulation of cell proliferation, apoptosis, and differentiation [19]. Previous studies demonstrated that gene amplification and increased expression of $c-M y c$ could promote the development of ovarian cancer $[20,21]$. PVT1 is located adjacent to $c-M Y C$ and functions as a noncoding RNA with many alternatively spliced isoforms. Both PVT1 copy number gains and overexpression have been implicated in the development of many tumors, including ovarian cancer [22]. Small interfering RNA-mediated reduction in either PVT1 or $M Y C$ expression can inhibit cellular proliferation of ovarian cancer [22].

The variant rs6983267 has been associated with both prostate and colorectal cancers in different ethnic populations [16, 23-25]. It is located far away from any coding sequences, and the nearest gene is $c-M Y C$. Functional studies suggest that rs6983267 is located in a transcriptional enhancer and exhibits long-range physical interaction with $c-M y c$ [26]. The variant has enhancerrelated histone marks and can form a $335-\mathrm{kb}$ chromatin loop to interact with the c-MYC promoter, resulting in elevated $c-M y c$ expression [27]. In addition, transpiration factors such as TCF4 may bind preferentially to the risk allele $\mathrm{G}$ of rs6983267, enhancing the responsiveness to Wnt signaling [28]. These findings provide a potential mechanism for the source of association between rs6983267 and ovarian cancer. However, additional studies are required to prove the interaction of rs6983267 with $c-M Y C$ and other transcription factors in the pathogenesis of ovarian cancer.

Previous studies identified rs13281615 at 8q24 as an independent susceptibility locus for breast cancer $[17,29]$. The GG genotype of rs13281615 was significantly associated with estrogen receptor positivity, higher tumor grade and higher proliferation index in breast cancer. In addition, PVT1 expression was elevated in breast cancer tissues and the increase was related with the GG genotype of rs13281615 [12]. Overexpression of PVT1 has been demonstrated in in a variety of cancer types including ovarian cancer [30]. Increased expression of PVT1 in ovarian cancer cells may promote cisplatin resistance by regulating apoptotic pathways [31]. In the current study, we did not find significant association between rs13281615 and ovarian cancer risk in Han Chinese women. However, insufficient statistical power due to relatively small sample size in our study may also account for the lack of association. Independent studies with larger sample size are needed to validate our results.

Several limitations need to be mentioned. First, for lacking of samples, we conducted only one stage case-control study. Second, the biological function of rs6983267 in ovarian cancer was not further investigated in this study. Despite these limitations, this study was the first to provide evidence that rs6983267 at 8q24 may 
Table 1: Demographic and clinical characteristics of ovarian cancer cases and controls

\begin{tabular}{|c|c|c|c|}
\hline Variables & $\begin{array}{c}\text { Case } \\
N=\mathbf{3 7 7}(\%)\end{array}$ & $\begin{array}{c}\text { Control } \\
N=1034(\%)\end{array}$ & $P^{\text {a }}$ \\
\hline Age, year $($ mean \pm SD) & $52.42 \pm 12.20$ & $52.75 \pm 11.91$ & 0.813 \\
\hline Age at menarche, year (mean $\pm \mathrm{SD}$ ) & $14.69 \pm 1.50$ & $16.13 \pm 1.20$ & $<0.001$ \\
\hline Abortion & & & $<0.001$ \\
\hline Yes & $153(40.58)$ & $257(24.85)$ & \\
\hline No & $204(54.11)$ & $686(66.34)$ & \\
\hline Unknown & $20(5.31)$ & $91(8.80)$ & \\
\hline Menopausal status & & & $<0.001$ \\
\hline Premenopausal & $126(33.42)$ & $465(44.97)$ & \\
\hline Postmenopausal & $224(59.42)$ & $546(52.80)$ & \\
\hline Unknown & $27(7.16)$ & $23(2.22)$ & \\
\hline Occupation & & & 0.433 \\
\hline Farmer & $155(41.11)$ & $386(37.33)$ & \\
\hline Worker & $57(15.12)$ & $167(16.15)$ & \\
\hline Other & $165(43.77)$ & $481(46.52)$ & \\
\hline Oral contraceptive & & & $<0.001$ \\
\hline Yes & $213(56.50)$ & 793(76.69) & \\
\hline No & $149(39.52)$ & 217(20.99) & \\
\hline Unknown & $15(3.98)$ & $24(2.32)$ & \\
\hline Family history of cancer & & & 0.757 \\
\hline Yes & $65(17.24)$ & $190(18.38)$ & \\
\hline No & $295(78.25)$ & $821(79.40)$ & \\
\hline Unknown & $17(4.51)$ & $23(2.22)$ & \\
\hline \multicolumn{4}{|l|}{ Histological type } \\
\hline Epithelial & $327(86.74)$ & & \\
\hline Other types ${ }^{\mathrm{b}}$ & $50(13.26)$ & & \\
\hline \multicolumn{4}{|l|}{ Stage } \\
\hline I or II & $103(27.32)$ & & \\
\hline III or IV & $274(72.68)$ & & \\
\hline
\end{tabular}

${ }^{a}$ Student's $t$ test and $\chi^{2}$ test were used for continuous and categorical variables, respectively

${ }^{\mathrm{b}}$ Other types included germ cell type and sex cord stromal type.

contribute to the risk of ovarian cancer in Han Chinese women. Replication studies in diverse populations and functional analyses are warranted to confirm the role of $8 \mathrm{q} 24$ variants in ovarian cancer.

\section{MATERIALS AND METHODS}

\section{Study population}

This study was approved by the institutional review board of Nanjing Medical University, and each participant signed an informed consent before the enrollment. Briefly, a total of 377 patients with ovarian cancer were recruited from the areas of relatively high incidence, including cities of Nantong, Wuxi and Nanjing in east China's Jiangsu province, as previously described [32]. All ovarian cancer cases had definite histopathological diagnosis and met the following inclusion criteria: (1) Han Chinese; (2) local residences (at least 5 years); (3) without tumor history in any other organs.

Cancer-free controls were randomly selected from a community-based cohort of over 30,000 participants for non-infectious disease screening program in Jiangsu Province, during the same period as the cases were recruited [33]. The controls were genetically unrelated Han Chinese women, having a local residence (at least 5 years) and no history of cancer. A one-on-one interview was carried out by a trained interviewer to collect 
Table 2: Main effects of rs13281615 and rs6983267 on ovarian cancer risk

\begin{tabular}{|c|c|c|c|c|c|c|}
\hline Genotypes & Case (\%) & Control (\%) & Crude OR $(95 \%$ CI) & $P$ & $\begin{array}{c}\text { Adjusted OR (95\% } \\
\text { CI) a }\end{array}$ & $P^{\text {a }}$ \\
\hline \multicolumn{7}{|l|}{ rs13281615 } \\
\hline $\mathrm{AA}$ & $86(23.06)$ & $279(26.98)$ & 1.00 & & 1.00 & \\
\hline $\mathrm{AG}$ & $192(51.47)$ & $503(48.65)$ & $1.24(0.92-1.66)$ & 0.153 & $1.25(0.92-1.71)$ & 0.159 \\
\hline GG & 95 (25.47) & $252(24.37)$ & $1.22(0.87-1.71)$ & 0.243 & $1.17(0.81-1.67)$ & 0.400 \\
\hline Dominant model & & & $1.23(0.94-1.63)$ & 0.139 & $1.22(0.91-1.64)$ & 0.181 \\
\hline Recessive model & & & $1.06(0.81-1.39)$ & 0.637 & $1.01(0.75-1.35)$ & 0.967 \\
\hline Additive model & & & $1.10(0.94-1.31)$ & 0.242 & $1.08(0.90-1.29)$ & 0.397 \\
\hline \multicolumn{7}{|l|}{ rs6983267 } \\
\hline TT & $128(33.95)$ & $394(38.10)$ & 1.00 & & 1.00 & \\
\hline GT & $183(48.54)$ & $510(49.32)$ & $1.11(0.85-1.43)$ & 0.456 & $1.07(0.81-1.41)$ & 0.631 \\
\hline GG & $66(17.51)$ & $130(12.57)$ & $1.56(1.09-2.23)$ & 0.014 & $1.57(1.06-2.32)$ & 0.023 \\
\hline Dominant model & & & $1.20(0.94-1.53)$ & 0.153 & $1.16(0.89-1.52)$ & 0.260 \\
\hline Recessive model & & & $1.48(1.07-2.04)$ & 0.018 & $1.51(1.06-2.15)$ & 0.023 \\
\hline Additive model & & & $1.22(1.03-1.45)$ & 0.026 & $1.21(1.01-1.43)$ & 0.048 \\
\hline
\end{tabular}

${ }^{a}$ Adjusted by age, age at menarche, abortion, menopausal status, and oral contraceptive.

Table 3: Stratified analysis of the association between rs6983267 and ovarian cancer risk

\begin{tabular}{|c|c|c|c|c|c|c|c|c|c|}
\hline \multirow{2}{*}{ Variables } & \multicolumn{3}{|c|}{ Case } & \multicolumn{3}{|c|}{ Control } & \multirow{2}{*}{$\operatorname{OR}(95 \% \mathrm{CI})^{\mathrm{a}}$} & \multirow{2}{*}{$P^{\text {a }}$} & \multirow{2}{*}{$P^{\mathrm{b}}$} \\
\hline & TT (\%) & GT (\%) & GG (\%) & TT (\%) & GT (\%) & GG (\%) & & & \\
\hline \multicolumn{10}{|l|}{ Age, year } \\
\hline$<52$ & $60(34.48)$ & $86(49.43)$ & $28(16.09)$ & $207(40.75)$ & $234(46.06)$ & $67(13.19)$ & $1.12(0.85-1.48)$ & 0.414 & 0.287 \\
\hline$\geq 52$ & $68(33.50)$ & $97(47.78)$ & $38(18.72)$ & $187(35.55)$ & $276(52.47)$ & $63(11.98)$ & $1.39(1.04-1.84)$ & 0.024 & \\
\hline \multicolumn{10}{|c|}{ Age at menarche, year } \\
\hline$<15$ & $56(32.56)$ & $83(48.26)$ & $33(19.19)$ & $82(36.61)$ & $113(50.45)$ & $29(12.95)$ & $1.18(0.90-1.53)$ & 0.229 & 0.430 \\
\hline$\geq 15$ & $63(33.69)$ & $93(49.73)$ & $31(16.58)$ & $310(38.41)$ & $396(49.07)$ & $101(12.52)$ & $1.40(1.00-1.94)$ & 0.050 & \\
\hline \multicolumn{10}{|l|}{ Abortion } \\
\hline Yes & $52(33.99)$ & $66(43.14)$ & $35(22.88)$ & $78(30.35)$ & $147(57.20)$ & $32(12.45)$ & $1.11(0.81-1.53)$ & 0.515 & 0.322 \\
\hline No & $68(33.33)$ & $110(53.92)$ & $26(12.75)$ & $281(40.96)$ & $327(47.67)$ & $78(11.37)$ & $1.31(1.02-1.69)$ & 0.033 & \\
\hline \multicolumn{10}{|l|}{ Menopausal status } \\
\hline Premenopausal & $36(28.57)$ & $65(51.59)$ & $25(19.84)$ & $186(40.00)$ & $221(47.53)$ & $58(12.47)$ & $1.62(1.18-2.23)$ & 0.003 & 0.037 \\
\hline Postmenopausal & $84(37.50)$ & $105(46.88)$ & $35(15.63)$ & $205(37.55)$ & $270(49.45)$ & $71(13.00)$ & $1.05(0.81-1.35)$ & 0.733 & \\
\hline \multicolumn{10}{|l|}{ Occupation } \\
\hline Farmer & $53(34.19)$ & $77(49.68)$ & $25(16.13)$ & $145(37.56)$ & $200(51.81)$ & $41(10.62)$ & $1.23(0.93-1.63)$ & 0.154 & 0.121 \\
\hline Worker & $14(24.56)$ & $33(57.89)$ & $10(17.54)$ & $76(45.51)$ & $73(43.71)$ & $18(10.78)$ & $1.84(1.17-2.89)$ & 0.008 & \\
\hline Other & $61(36.97)$ & $73(44.24)$ & $31(18.79)$ & $173(35.97)$ & $237(49.27)$ & $71(14.76)$ & $1.07(0.83-1.37)$ & 0.628 & \\
\hline \multicolumn{10}{|l|}{ Oral contraceptive } \\
\hline Yes & $71(33.33)$ & $104(48.83)$ & $38(17.84)$ & $303(38.21)$ & $392(49.43)$ & $98(12.36)$ & $1.23(0.97-1.56)$ & 0.093 & 0.970 \\
\hline No & $52(34.90)$ & $70(46.98)$ & $27(18.12)$ & $82(37.96)$ & $108(50.00)$ & $26(12.04)$ & $1.24(0.87-1.75)$ & 0.238 & \\
\hline \multicolumn{10}{|c|}{ Family history of cancer } \\
\hline Yes & $21(32.31)$ & $33(50.77)$ & $11(16.92)$ & $64(33.68)$ & $93(48.95)$ & $33(17.37)$ & $1.09(0.61-1.93)$ & 0.774 & 0.593 \\
\hline No & $103(34.92)$ & $140(47.46)$ & $52(17.63)$ & $322(39.22)$ & $405(49.33)$ & $94(11.45)$ & $1.29(1.03-1.61)$ & 0.027 & \\
\hline
\end{tabular}

${ }^{a}$ Adjusted for age, age at menarche, abortion, menopausal status, and oral contraceptive where appropriate in additive models.

${ }^{\mathrm{b}} P$ for heterogeneity test. 
demographic information, age at menarche, menstrual and reproduction history, and environmental exposures. Approximately $5 \mathrm{ml}$ of venous blood was obtained from each participant. Eventually, 377 ovarian cancer cases and 1034 cancer-free controls frequency-matched by age (5year interval) were included in this study.

\section{Genotyping}

Genomic DNA was extracted from leukocyte pellets by traditional proteinase $\mathrm{K}$ digestion, followed by phenolchloroform extraction and ethanol precipitation. Variants were genotyped using the TaqMan allelic discrimination assay on ABI PRISM 7900 HT platform (Life Technologies, CarIsbad, USA). Information of the primers and probes was shown in Supplementary Table 1. The genotyping was performed without knowing the subjects' case or control status. In each 384-well reaction plate, two negative controls were added for quality control. To make sure the reproducibility of genotyping, 50 cases and 50 controls were randomly selected to be retested, yielding a $100 \%$ concordance.

\section{Statistical analysis}

Differences in demographic characteristics, exposure variables, and genotypes frequencies between the cases and controls were evaluated by the $\chi^{2}$ test for categorical variables and Student's t test for continuous variables. Hardy-Weinberg equilibrium (HWE) was tested using goodness-of-fit $\chi^{2}$ test. Haploview was employed to analyze linkage disequilibrium (LD) parameters (i.e., $\mathrm{D}^{\prime}$ and $\mathrm{r}^{2}$ ). The association between variants and ovarian cancer risk was estimated by computing odds ratios (ORs) and their 95\% confidence intervals (CIs) from logistic regression analysis in three genetic models (additive, dominant, and recessive). Each model makes different assumptions about the genetic effect, as previously described [34]. Age and statistically significant variables in univariate analysis were included in multivariate analysis. In stratified analysis, the $\chi^{2}$-based $Q$ test was used to assess the heterogeneity of associations between subgroups. All statistical analyses were performed with Statistical Analysis System software (v9.1.3, SAS Institute, Cary, NC). A two-sided $P$ value of less than 0.05 was used as the criterion for statistical significance.

\section{ACKNOWLEDGMENTS AND FUNDING}

This work was supported by National Natural Science Foundation of China (grant no. 81502873), Natural Science Foundation of Jiangsu Province for Youth (grant no. BK20150997), Natural Science Foundation of the Higher Education Institutions of Jiangsu Province (grant no. 15KJB330001), Science Foundation for Distinguished Young Scholars of Jiangsu (BK20160046), the Priority Academic Program for the Development of Jiangsu Higher Education Institutions (Public Health and Preventive Medicine), and Top-notch Academic Programs Project of Jiangsu Higher Education Institutions (PPZY2015A067), Technology Development Foundation of Nanjing Medical University (2014NJMU078).

\section{CONFLICTS OF INTEREST}

The authors declare no conflicts of interest.

\section{REFERENCES}

1. Torre LA, Bray F, Siegel RL, Ferlay J, Lortet-Tieulent J, Jemal A. Global cancer statistics. CA Cancer J Clin. 2015; 65:87-108.

2. Le ND, Leung A, Brooks-Wilson A, Gallagher RP, Swenerton KD, Demers P, Cook LS. Occupational exposure and ovarian cancer risk. Cancer Causes Control. 2014; 25:829-841.

3. Tsilidis KK, Allen NE, Key TJ, Dossus L, Lukanova A, Bakken K, Lund E, Fournier A, Overvad K, Hansen L, Tjonneland A, Fedirko V, Rinaldi S, et al. Oral contraceptive use and reproductive factors and risk of ovarian cancer in the European Prospective Investigation into Cancer and Nutrition. Br J Cancer. 2011; 105:1436-1442.

4. Collaborative Group on Epidemiological Studies of Ovarian C, Beral V, Doll R, Hermon C, Peto R, Reeves G. Ovarian cancer and oral contraceptives: collaborative reanalysis of data from 45 epidemiological studies including 23,257 women with ovarian cancer and 87,303 controls. Lancet. 2008; 371:303-314.

5. Koeneman MM, Kruse AJ, Sep SJ, Gubbels CS, Slangen BF, van Gorp T, Lopes A, Gomez-Garcia E, Kruitwagen RF. A family history questionnaire improves detection of women at risk for hereditary gynecologic cancer: a pilot study. Fam Cancer. 2014; 13:469-475.

6. Al Bakir M, Gabra H. The molecular genetics of hereditary and sporadic ovarian cancer: implications for the future. $\mathrm{Br}$ Med Bull. 2014; 112:57-69.

7. Gudmundsson J, Sulem P, Manolescu A, Amundadottir LT, Gudbjartsson D, Helgason A, Rafnar T, Bergthorsson JT, Agnarsson BA, Baker A, Sigurdsson A, Benediktsdottir KR, Jakobsdottir M, et al. Genome-wide association study identifies a second prostate cancer susceptibility variant at 8q24. Nat Genet. 2007; 39:631-637.

8. Zhang B, Jia WH, Matsuda K, Kweon SS, Matsuo K, Xiang YB, Shin A, Jee SH, Kim DH, Cai Q, Long J, Shi J, Wen W, et al. Large-scale genetic study in East Asians identifies six new loci associated with colorectal cancer risk. Nat Genet. 2014; 46:533-542.

9. Turnbull C, Ahmed S, Morrison J, Pernet D, Renwick A, Maranian M, Seal S, Ghoussaini M, Hines S, Healey CS, Hughes D, Warren-Perry M, Tapper W, et al. Genome- 
wide association study identifies five new breast cancer susceptibility loci. Nat Genet. 2010; 42:504-507.

10. Goode EL, Chenevix-Trench G, Song H, Ramus SJ, Notaridou M, Lawrenson K, Widschwendter M, Vierkant RA, Larson MC, Kjaer SK, Birrer MJ, Berchuck A, Schildkraut J, et al. A genome-wide association study identifies susceptibility loci for ovarian cancer at $2 \mathrm{q} 31$ and 8q24. Nat Genet. 2010; 42:874-879.

11. Wang YH, Liu S, Zhang G, Zhou CQ, Zhu HX, Zhou XB, Quan LP, Bai J, Xu NZ. Knockdown of c-Myc expression by RNAi inhibits MCF-7 breast tumor cells growth in vitro and in vivo. Breast Cancer Res. 2005; 7:R220-228.

12. Zhang Z, Zhu Z, Zhang B, Li W, Li X, Wu X, Wang L, $\mathrm{Fu}$ L, Dong JT. Frequent mutation of rs13281615 and its association with PVT1 expression and cell proliferation in breast cancer. J Genet Genomics. 2014; 41:187-195.

13. Yeager M, Chatterjee N, Ciampa J, Jacobs KB, GonzalezBosquet J, Hayes RB, Kraft P, Wacholder S, Orr N, Berndt S, Yu K, Hutchinson A, Wang Z, et al. Identification of a new prostate cancer susceptibility locus on chromosome 8q24. Nat Genet. 2009; 41:1055-1057.

14. Tomlinson I, Webb E, Carvajal-Carmona L, Broderick P, Kemp Z, Spain S, Penegar S, Chandler I, Gorman M, Wood W, Barclay E, Lubbe S, Martin L, et al. A genomewide association scan of tag SNPs identifies a susceptibility variant for colorectal cancer at 8q24.21. Nat Genet. 2007; 39:984-988.

15. Zanke BW, Greenwood CM, Rangrej J, Kustra R, Tenesa A, Farrington SM, Prendergast J, Olschwang S, Chiang T, Crowdy E, Ferretti V, Laflamme P, Sundararajan S, et al. Genome-wide association scan identifies a colorectal cancer susceptibility locus on chromosome 8q24. Nat Genet. 2007; 39:989-994.

16. Haiman CA, Le Marchand L, Yamamato J, Stram DO, Sheng X, Kolonel LN, Wu AH, Reich D, Henderson BE. A common genetic risk factor for colorectal and prostate cancer. Nat Genet. 2007; 39:954-956.

17. Easton DF, Pooley KA, Dunning AM, Pharoah PD, Thompson D, Ballinger DG, Struewing JP, Morrison J, Field H, Luben R, Wareham N, Ahmed S, Healey CS, et al. Genome-wide association study identifies novel breast cancer susceptibility loci. Nature. 2007; 447:1087-1093.

18. Du M, Yuan T, Schilter KF, Dittmar RL, Mackinnon A, Huang X, Tschannen M, Worthey E, Jacob H, Xia S, Gao J, Tillmans L, Lu Y, et al. Prostate cancer risk locus at 8q24 as a regulatory hub by physical interactions with multiple genomic loci across the genome. Hum Mol Genet. 2015; 24:154-166.

19. Nilsson J, Cleveland JL. Myc pathways provoking cell suicide and cancer. Oncogene. 2003; 22:9007-9021.

20. Wang ZR, Liu W, Smith ST, Parrish R, Young SR. c-Myc and chromosome 8 centromere studies of ovarian cancer by interphase FISH. Exp Mol Pathol. 1999; 66:140-148.
21. Chen CH, Shen J, Lee W, Chow SN. Overexpression of cyclin D1 and c-Myc gene products in human primary epithelial ovarian cancer. Int J Gynecol Cancer. 2005; 15:878-883.

22. Guan Y, Kuo WL, Stilwell JL, Takano H, Lapuk AV, Fridlyand J, Mao JH, Yu M, Miller MA, Santos JL, Kalloger SE, Carlson JW, Ginzinger DG, et al. Amplification of PVT1 contributes to the pathophysiology of ovarian and breast cancer. Clin Cancer Res. 2007; 13:5745-5755.

23. Yeager M, Orr N, Hayes RB, Jacobs KB, Kraft P, Wacholder S, Minichiello MJ, Fearnhead P, Yu K, Chatterjee N, Wang Z, Welch R, Staats BJ, et al. Genomewide association study of prostate cancer identifies a second risk locus at 8q24. Nat Genet. 2007; 39:645-649.

24. Yang Y, Wang W, Zhang L, Zhang S, Liu G, Yu Y, Liao M. Association of single nucleotide polymorphism rs6983267 with the risk of prostate cancer. Oncotarget. 2016; 7:25528-25534. doi: 10.18632/oncotarget.8186.

25. Hong Y, Wu G, Li W, Liu D, He K. A comprehensive metaanalysis of genetic associations between five key SNPs and colorectal cancer risk. Oncotarget. 2016; 7:73945-73959. doi: 10.18632/oncotarget.12154.

26. Pomerantz MM, Ahmadiyeh N, Jia L, Herman P, Verzi MP, Doddapaneni H, Beckwith CA, Chan JA, Hills A, Davis M, Yao K, Kehoe SM, Lenz HJ, et al. The 8q24 cancer risk variant rs6983267 shows long-range interaction with MYC in colorectal cancer. Nat Genet. 2009; 41:882-884.

27. Wright JB, Brown S, Cole MD. Upregulation of c-MYC in cis through a large chromatin loop linked to a cancer riskassociated single-nucleotide polymorphism in colorectal cancer cells. Mol Cell Biol. 2010; 30:1411-1420.

28. Tuupanen S, Turunen M, Lehtonen R, Hallikas O, Vanharanta S, Kivioja T, Bjorklund M, Wei G, Yan J, Niittymaki I, Mecklin JP, Jarvinen H, Ristimaki A, et al. The common colorectal cancer predisposition SNP rs6983267 at chromosome $8 \mathrm{q} 24$ confers potential to enhanced Wnt signaling. Nat Genet. 2009; 41:885-890.

29. Michailidou K, Hall P, Gonzalez-Neira A, Ghoussaini M, Dennis J, Milne RL, Schmidt MK, Chang-Claude J, Bojesen SE, Bolla MK, Wang Q, Dicks E, Lee A, et al. Large-scale genotyping identifies 41 new loci associated with breast cancer risk. Nat Genet. 2013; 45:353-361, 361e351-352.

30. Cui M, You L, Ren X, Zhao W, Liao Q, Zhao Y. Long non-coding RNA PVT1 and cancer. Biochem Biophys Res Commun. 2016; 471:10-14.

31. Liu E, Liu Z, Zhou Y, Mi R, Wang D. Overexpression of long non-coding RNA PVT1 in ovarian cancer cells promotes cisplatin resistance by regulating apoptotic pathways. Int J Clin Exp Med. 2015; 8:20565-20572.

32. Li DK, Han J, Liu JB, Jin GF, Qu JW, Zhu M, Wang YR, Jiang J, Ma HX. Genetic variants at $6 \mathrm{p} 21.1$ and $7 \mathrm{p} 15.3$ Identified by GWASs of multiple cancers and ovarian 
cancer risk: a case-control study in Han Chinese women. Asian Pac J Cancer Prev. 2014; 15:123-127.

33. Qian Y, Lu F, Dong M, Lin Y, Li H, Chen J, Shen C, Jin G, $\mathrm{Hu} \mathrm{Z}$, Shen H. Genetic variants of IDE-KIF11-HHEX at $10 \mathrm{q} 23.33$ associated with type 2 diabetes risk: a finemapping study in Chinese population. PLoS One. 2012; 7:e35060.
34. Lettre G, Lange C, Hirschhorn JN. Genetic model testing and statistical power in population-based association studies of quantitative traits. Genet Epidemiol. 2007; 31:358-362. 